\title{
Thermodynamic Assessment of V-Rare Earth Systems
}

\author{
Wren Chan, Michael C. Gao, Ömer N. Doğan, and Paul King
}

(Submitted March 24, 2010; in revised form June 16, 2010)

\begin{abstract}
Vanadium is a refractory metal with high melting point $\left(1910{ }^{\circ} \mathrm{C}\right)$ that has good structural strength, good room-temperature corrosion resistance, and low thermal neutron-absorption cross section. Vanadium is primarily used as a steel additive to improve the strength of steels by forming stable nitrides and carbides. Addition of yttrium to vanadium alloys can improve the oxidation resistance and mechanical properties. In this work, three binary systems, V-Ce, V-La, and V-Y, were thermodynamically assessed based on the ASM Binary Alloy Phase Diagrams using CALPHAD approach. Self-consistent thermodynamic descriptions for all three systems were obtained.
\end{abstract}

Keywords CALPHAD, refractory metals, V-Ce, V-La, V-Y

\section{Introduction}

Vanadium based alloys are leading candidates for application in nuclear technology specifically fusion firstwall/blanket applications. ${ }^{[1]}$ Vanadium alloys have "good fabricability, high temperature and heat load capability, good compatibility with liquid metals and resistance to irradiation damage effects." $" 1]$ Another promising application of vanadium based alloys is in energy storage such as hydrogen storage in extremely high working temperature. ${ }^{[2]}$ Furthermore, vanadium is used primarily as an alloying agent in steel (ferrovanadium) for an increase in tensile strength and high temperature strength in addition to its "grain refining and dispersion hardening effect" on tempered steel. ${ }^{[3]}$ In addition, it is also alloyed with titanium to obtain "good strength properties at room temperature and good creep resistance.", 3 ]

On the other hand, addition of rare earth elements (e.g., $\mathrm{Y}$ ) brings superior oxidation resistance to $\mathrm{V}-4 \mathrm{Cr}-4 \mathrm{Ti}$ alloys at 600 and $700{ }^{\circ} \mathrm{C}$ by preventing surface $\mathrm{V}_{2} \mathrm{O}_{5}$ formation. ${ }^{[4]}$ Utilizing mechanical alloying and hot isostatic pressing, Kurishita et al. ${ }^{[5]}$ fabricated a Cr-44.2V-1.8Y (wt.\%) alloy that achieved a yield strength of $610-740 \mathrm{MPa}$ and a total elongation of $10-19 \%$ at room temperature. The combination of improved ductility and high strength was attributed to very fine grain sizes of bcc matrix and fine dispersion of $\mathrm{Y}_{2} \mathrm{O}_{3}$ particles. ${ }^{[5]}$ Improvement in oxidation resistance and mechanical properties of $\mathrm{V}$-based alloys due to yttrium addition promotes us to study the thermodynamics of vanadium-rare earth (RE) element systems. Developing an

Wren Chan, Department of Materials Science and Engineering, Carnegie Mellon University, Pittsburgh, PA 15213; Michael C. Gao, Ömer N. Doğan, and Paul King, National Energy Technology Laboratory, 1450 Queen Ave SW, Albany, OR 97321-2198; Michael C. Gao, URS Corp, P.O. Box 1959, Albany, OR 97321-0521. Contact e-mail: michael.gao@netl.doe.gov. accurate self-consistent thermodynamic database for V-RE systems in turn will facilitate new alloy design and help optimize process control (e.g., heat treatment). In the present study, the CALPHAD (acronym of calculation of phase diagram) method is used to model the thermodynamics of $\mathrm{V}-\mathrm{Ce}, \mathrm{V}-\mathrm{La}$, and V-Y binary systems based on available phase equilibria data in the literature.

\section{Literature Information}

Experimental investigations in these systems discussed below are limited and generally confined to the solubility limits and invariant reactions. There are no intermetallic compounds for these binary systems which indicate a repulsive interaction between $\mathrm{V}$ and the three rare earth elements. For these systems, the terminal solubilities are negligible and a liquid miscibility gap exists. The currently accepted phase diagrams ${ }^{[6]}$ for all three systems are based on calculated phase diagrams by Smith and Lee ${ }^{[7]}$ (see Fig. 1). Due to the uncertainty of the accuracy of the available experimental data on solubility and invariant composition and temperature, they are largely not used for the present optimization. Instead, the thermodynamic assessment in this study utilizes the currently accepted phase diagrams ${ }^{[6,7]}$ as a guide. These systems were reviewed by both Gschneidner ${ }^{[8]}$ and Smith and Lee. ${ }^{[7]}$

\subsection{V-Ce System}

The terminal phases of the $\mathrm{V}-\mathrm{Ce}$ system are $\mathrm{V}$ (bcc), $\beta \mathrm{Ce}$ (dhcp), $\gamma \mathrm{Ce}$ (fcc), and $\delta \mathrm{Ce}$ (bcc) above room temperature. Smith and Lee ${ }^{[7]}$ (see Fig. 1a) was particularly helpful in summarizing the results of several studies. The calculated phase diagram by Smith and Lee ${ }^{[7]}$ qualitatively incorporates all the invariant reactions reported by Efimov ${ }^{[9]}$ with some degree of uncertainty in temperature and composition. In particular, both Efimov ${ }^{[9]}$ and Savitskii et al. ${ }^{[10]}$ indicated a peritectic reaction $(\mathrm{L}+\mathrm{V} \leftrightarrow \delta \mathrm{Ce})$ at $810 \pm 5{ }^{\circ} \mathrm{C}$ and a eutectoid reaction $(\delta \mathrm{Ce} \leftrightarrow \mathrm{V}+\gamma \mathrm{Ce})$ at $705 \pm 5{ }^{\circ} \mathrm{C}$. These reactions account for a peritectic elevation of the melting of 

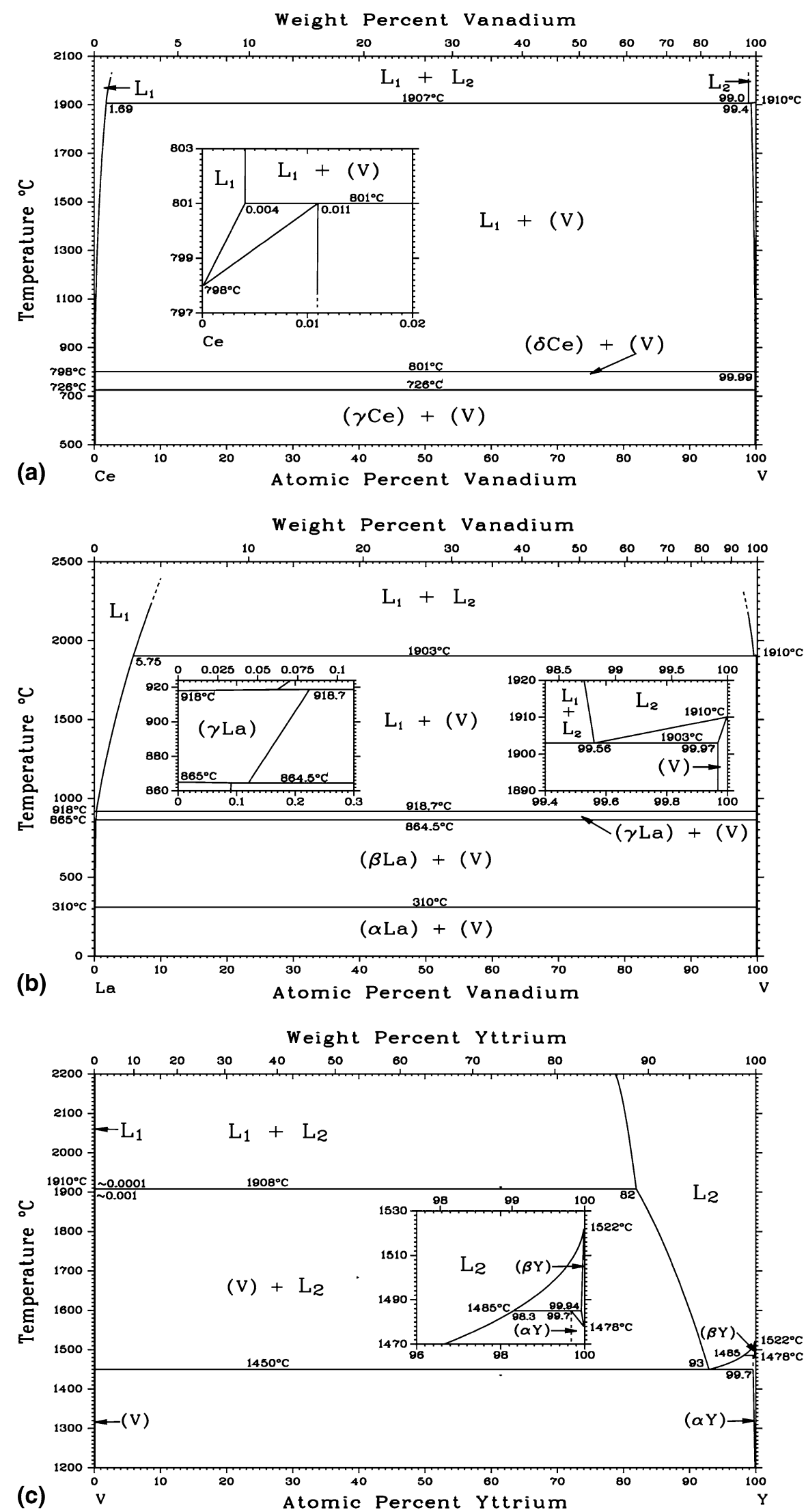

Fig. 1 Assessed (a) Ce-V, (b) La-V, and (c) V-Y binary phase diagrams in the ASM handbook ${ }^{[6]}$ 
Table 1 Thermodynamic parameters of the V-X $(\mathrm{X}=\mathrm{Ce}, \mathrm{La}, \mathrm{Y})$ systems (J/mol of atoms) optimized in the present study

\begin{tabular}{lll}
\hline V-Ce system & \multicolumn{1}{c}{ V-La system } & \multicolumn{1}{c}{ V-Y system } \\
\hline Liquid & Liquid & Liquid \\
${ }^{0} L_{\mathrm{V}, \mathrm{Ce}}=84,310-4.345 T$ & ${ }^{0} L_{\mathrm{V}, \mathrm{La}}=72,604$ & ${ }^{0} L_{\mathrm{V}, \mathrm{Y}}=19,195+15.853 T$ \\
& ${ }^{1} L_{\mathrm{V}, \mathrm{La}}=-18,950$ & ${ }^{1} L_{\mathrm{V}, \mathrm{Y}}=23,522$ \\
& & ${ }^{2} L_{\mathrm{V}, \mathrm{Y}}=21,538$ \\
$\mathrm{BCC}-\mathrm{A} 2$ & $\mathrm{BCC}-\mathrm{A} 2$ & $\mathrm{BCC}-\mathrm{A} 2$ \\
${ }^{0} L_{\mathrm{V}, \mathrm{Ce}}=105,731$ & ${ }^{0} L_{\mathrm{V}, \mathrm{La}}=98,843$ & ${ }^{0} L_{\mathrm{V}, \mathrm{Y}}=113,047$ \\
${ }^{1} L_{\mathrm{V}, \mathrm{Ce}}=-24,471$ & ${ }^{1} L_{\mathrm{V}, \mathrm{La}}=-37,743$ & ${ }^{1} L_{\mathrm{V}, \mathrm{Y}}=17,705$ \\
FCC-A1 & FCC-A 1 & $\mathrm{HCP}-\mathrm{A} 3$ \\
${ }^{0} L_{\mathrm{V}, \mathrm{Ce}}=328,391$ & ${ }^{0} L_{\mathrm{V}, \mathrm{La}}=55,758$ & ${ }^{0} L_{\mathrm{V}, \mathrm{Y}}=70,170$ \\
& &
\end{tabular}

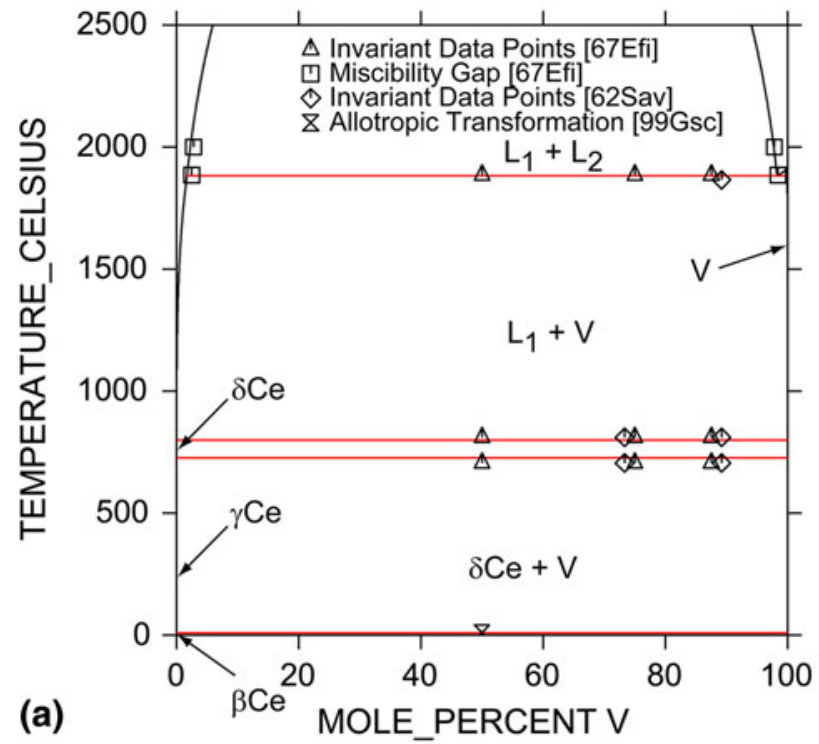

Ce $\left(798^{\circ} \mathrm{C}\right)$ and a eutectoid depression of the fcc $\leftrightarrow$ bcc phase transition $\left(726^{\circ} \mathrm{C}\right)$. The invariant shifts are believed to be due to the impurities in the $\mathrm{V}$ samples used in the experiments. Smith and Lee ${ }^{[7]}$ believe that the shifts indicate some solubility of $\mathrm{V}$ in $\mathrm{Ce}$. The temperature for the monotectic reaction $\left(\mathrm{L}_{2} \leftrightarrow \mathrm{L}_{1}+\mathrm{V}\right)$ is given by both Efimov $^{[9]}$ and Savitskii et al. ${ }^{[10]}$ as $1885 \pm 15^{\circ} \mathrm{C}$. The monotectic invariant temperature is nearly $25^{\circ} \mathrm{C}$ below the currently accepted melting point of $\mathrm{V}\left(1910^{\circ} \mathrm{C}\right)$ and is accounted for due to impurities. Smith and Lee ${ }^{[7]}$ cited a later study by Savitskii ${ }^{[1]}$ which indicated a depression of around $2{ }^{\circ} \mathrm{C}$ in the superconducting transition of $\mathrm{V}$ with the addition of $\mathrm{Ce}$ in $\mathrm{V}$ that reinforced the very low solubility of $\mathrm{Ce}$ in both solid and liquid V. The monotectic composition is given by Efimov ${ }^{[9]}$ and presented in Table 2 .

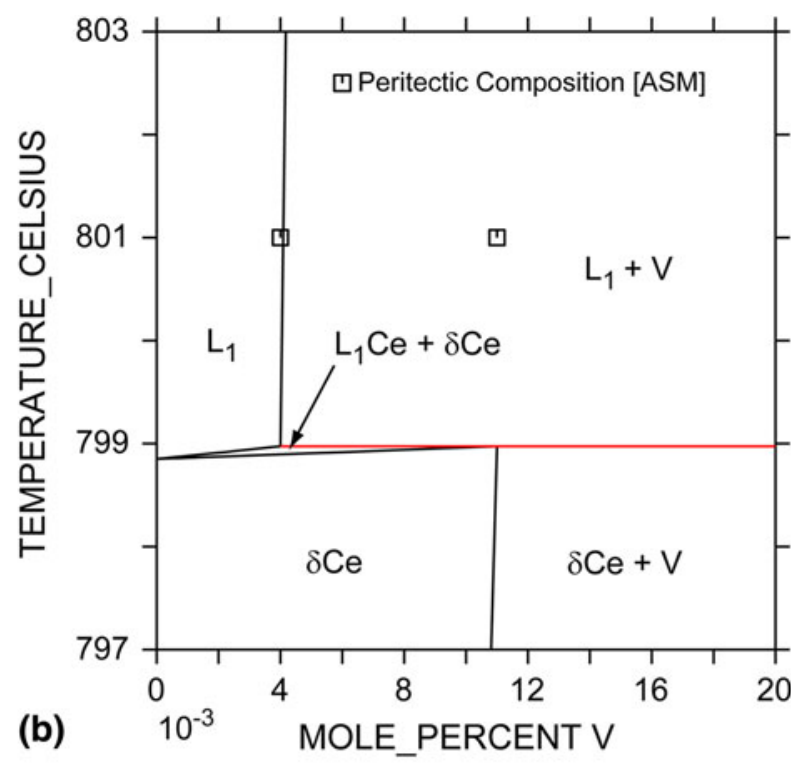

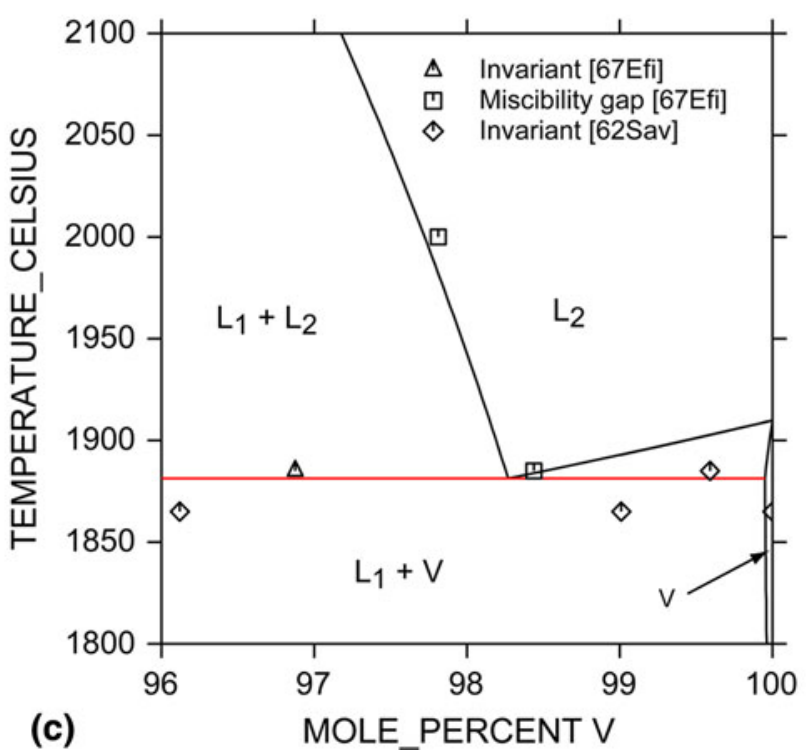

Fig. 2 (a) Calculated phase diagram of the V-Ce system compared with experimental points. ${ }^{[9,10,20]}$ (b) Enlarged Ce-rich side of the V-Ce phase diagram compared with the handbook. ${ }^{[6]}$ (c) Enlarged V-rich side of the V-Ce phase diagram compared with the handbook ${ }^{[9,10]}$ 
Table 2 Invariant reactions in the $\mathrm{V}$-Ce system compared with the literature ${ }^{[6,9,10,14,20]}$

\begin{tabular}{|c|c|c|c|c|c|}
\hline \multirow{2}{*}{$\begin{array}{l}\text { Invariant reactions } \\
\mathrm{L}_{2} \leftrightarrow \mathrm{L}_{1}+\mathrm{V}\end{array}$} & \multirow{2}{*}{$\begin{array}{c}\boldsymbol{T},{ }^{\circ} \mathbf{C} \\
1885 \pm 15\end{array}$} & \multicolumn{3}{|c|}{$V$ concentration (at. $\%$ ) } & \multirow{2}{*}{$\begin{array}{l}\text { Reference } \\
{[9]}\end{array}$} \\
\hline & & 99.9 & 1.6 & 99.95 & \\
\hline & 1907 & 99.0 & 1.69 & 99.4 & {$[6,14]$} \\
\hline & 1881 & 98.27 & 1.73 & 99.95 & This study \\
\hline \multirow[t]{3}{*}{$\mathrm{L}+\mathrm{V} \leftrightarrow \delta \mathrm{Ce}$} & $810 \pm 5$ & $\mathrm{n} / \mathrm{a}$ & $\mathrm{n} / \mathrm{a}$ & $\mathrm{n} / \mathrm{a}$ & {$[9,10]$} \\
\hline & 801 & 0.004 & 99.99+ & $\sim 0.011$ & {$[6,14]$} \\
\hline & 799 & 0.004 & $\sim 100$ & $\sim 0.011$ & This study \\
\hline \multirow[t]{3}{*}{$\delta \mathrm{Ce} \leftrightarrow \mathrm{V}+\gamma \mathrm{Ce}$} & $705 \pm 5$ & $\mathrm{n} / \mathrm{a}$ & $\mathrm{n} / \mathrm{a}$ & $\mathrm{n} / \mathrm{a}$ & {$[9,10]$} \\
\hline & 726 & $\mathrm{n} / \mathrm{a}$ & $\mathrm{n} / \mathrm{a}$ & $\mathrm{n} / \mathrm{a}$ & {$[6,14]$} \\
\hline & 726.7 & $\sim 0$ & $\sim 100$ & $\sim 0$ & This study \\
\hline \multirow[t]{3}{*}{$\gamma \mathrm{Ce} \leftrightarrow \mathrm{V}+\beta \mathrm{Ce}$} & 61 & $\mathrm{n} / \mathrm{a}$ & $\mathrm{n} / \mathrm{a}$ & $\mathrm{n} / \mathrm{a}$ & {$[6,14]$} \\
\hline & 10 & $\mathrm{n} / \mathrm{a}$ & $\mathrm{n} / \mathrm{a}$ & $\mathrm{n} / \mathrm{a}$ & [20] \\
\hline & 9.85 & $\sim 0$ & $\sim 100$ & $\sim 0$ & This study \\
\hline
\end{tabular}

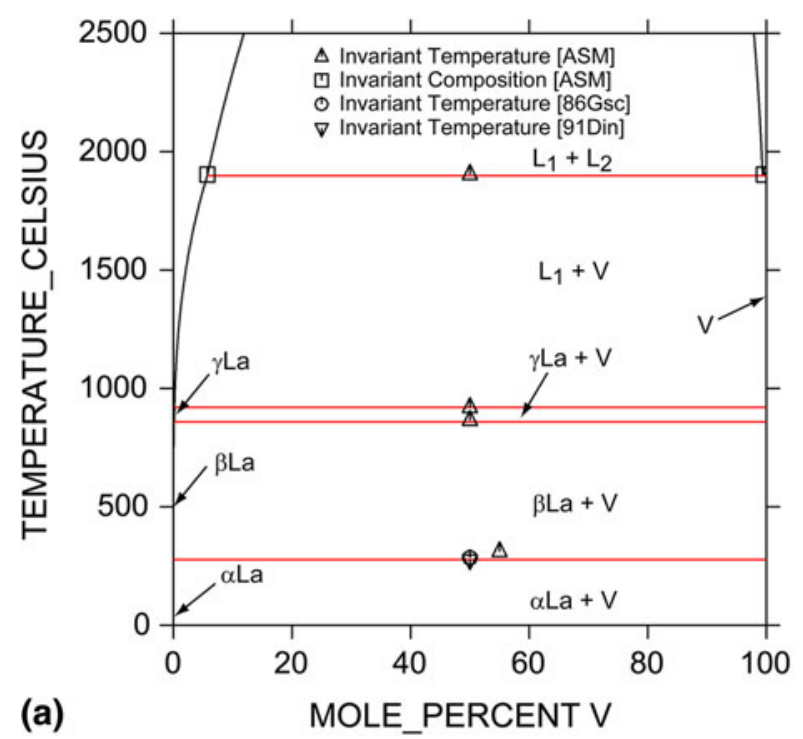

\subsection{V-La System}

The terminal phases of the V-La system are V (bcc), $\alpha \mathrm{La}$ (dhcp), $\beta \mathrm{La}$ (fcc), and $\gamma \mathrm{La}$ (bcc) above room temperature. Like the V-Ce system, Smith and Lee ${ }^{[7]}$ (see Fig. 1b) also highlighted the results from earlier studies. Gschneidner ${ }^{[8]}$ reviewed a study by Savitskii ${ }^{[12]}$; it has not been possible to obtain a copy of the Saviatskii report but Gschneiner quoted the Savitskii values for the invariant reaction associated with the fcc $\leftrightarrow$ bcc La transition as $675^{\circ} \mathrm{C}$ and that with the melting of $\mathrm{La}$ as $865^{\circ} \mathrm{C}$, "whereas the currently accepted values are 865 and $918{ }^{\circ} \mathrm{C}$." [7] This suggests that the La used was probably impure and a schematic phase diagram drawn by Gschneidner adjusted the temperatures to become 895 and $930{ }^{\circ} \mathrm{C}$, respectively, as peritectoid $(\gamma \mathrm{La}+\mathrm{V} \leftrightarrow$ $\beta \mathrm{La})$ and peritectic ( $\mathrm{L}+\mathrm{V} \leftrightarrow \gamma \mathrm{La})$ reactions. The large shifts in the two invariant reactions are retained in Efimov's

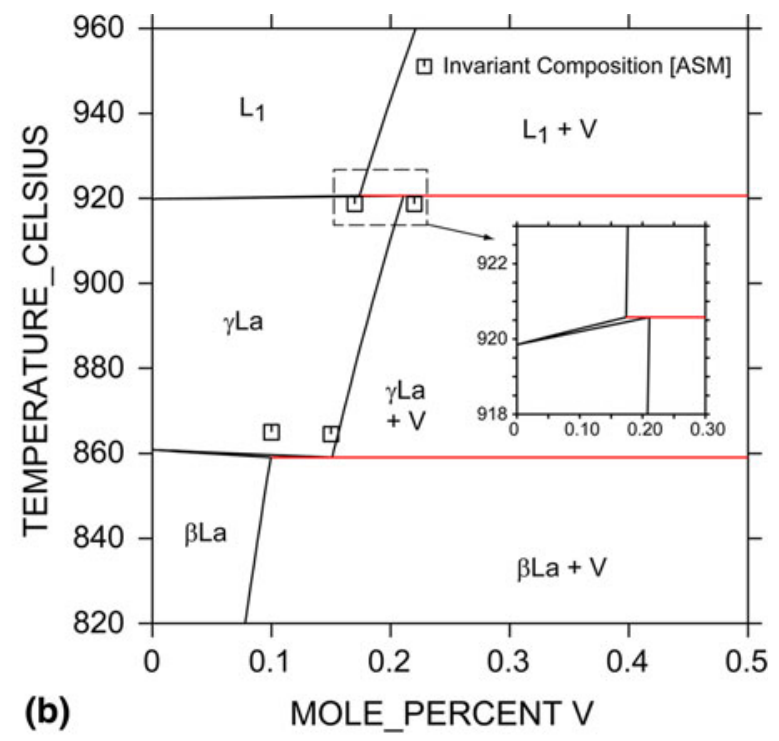

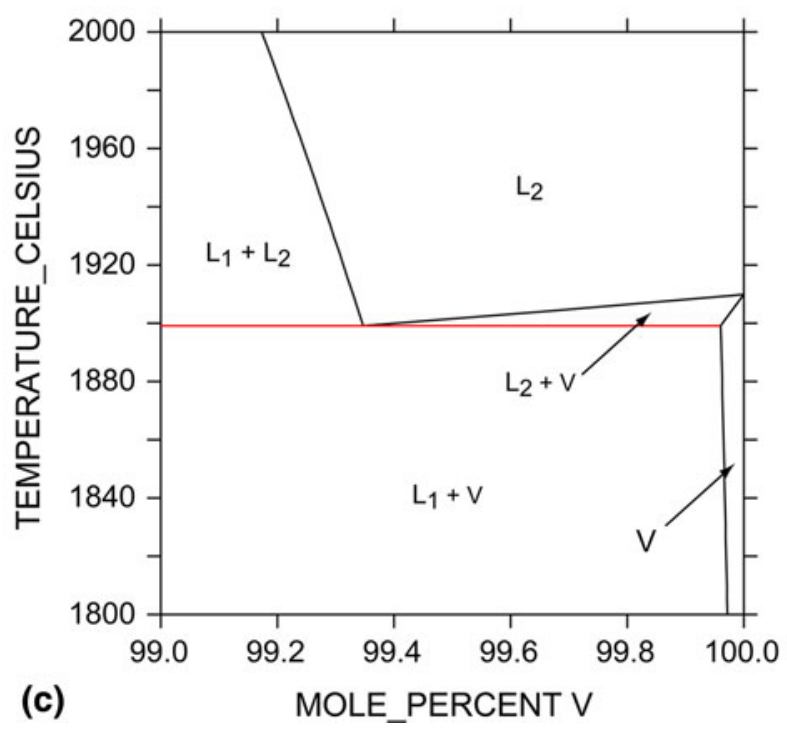

Fig. 3 (a) Calculated phase diagram of the V-La system compared with the handbook ${ }^{[6]}$. (b) Enlarged La-rich side of the V-La phase diagram. (c) Enlarged V-rich side of the V-La phase diagram 
Table 3 Invariant reactions in the V-La system compared with the literature ${ }^{[6,8,9,14]}$

\begin{tabular}{|c|c|c|c|c|c|}
\hline \multirow{2}{*}{$\frac{\text { Invariant reactions }}{\mathrm{L}_{2} \leftrightarrow \mathrm{L}_{1}+\mathrm{V}}$} & \multirow{2}{*}{$\frac{T,{ }^{\circ} \mathrm{C}}{1680}$} & \multicolumn{3}{|c|}{$V$ concentration, at. $\%$} & \multirow{2}{*}{$\begin{array}{l}\text { Reference } \\
{[8]}\end{array}$} \\
\hline & & $\mathrm{n} / \mathrm{a}$ & $\mathrm{n} / \mathrm{a}$ & $\mathrm{n} / \mathrm{a}$ & \\
\hline & 1680 & 5 & $\mathrm{n} / \mathrm{a}$ & $\mathrm{n} / \mathrm{a}$ & [9] \\
\hline & 1903 & 99.56 & 5.75 & 99.97 & {$[6,14]$} \\
\hline & 1899 & 99.35 & 5.73 & 99.96 & This study \\
\hline \multirow[t]{4}{*}{$\mathrm{L}+\mathrm{V} \leftrightarrow \gamma \mathrm{La}$} & 930 & $\mathrm{n} / \mathrm{a}$ & $\mathrm{n} / \mathrm{a}$ & $\mathrm{n} / \mathrm{a}$ & \\
\hline & 890 & $\mathrm{n} / \mathrm{a}$ & $\mathrm{n} / \mathrm{a}$ & $\mathrm{n} / \mathrm{a}$ & [9] \\
\hline & 920 & 0.17 & 99.9999 & 0.22 & {$[6,14]$} \\
\hline & 920.6 & 0.17 & $\sim 100$ & 0.21 & This study \\
\hline \multirow[t]{4}{*}{$\gamma \mathrm{La} \leftrightarrow \mathrm{V}+\beta \mathrm{La}$} & 895 & $\mathrm{n} / \mathrm{a}$ & $\mathrm{n} / \mathrm{a}$ & $\mathrm{n} / \mathrm{a}$ & \\
\hline & 700 & $\mathrm{n} / \mathrm{a}$ & $\mathrm{n} / \mathrm{a}$ & $\mathrm{n} / \mathrm{a}$ & [9] \\
\hline & 865 & $>0.1$ & 99.99999 & $<0.1$ & {$[6,14]$} \\
\hline & 864.5 & 0.15 & $\sim 100$ & 0.0995 & This study \\
\hline \multirow[t]{4}{*}{$\beta \mathrm{La} \leftrightarrow \mathrm{V}+\alpha \mathrm{La}$} & 310 & $\sim 0$ & $\mathrm{n} / \mathrm{a}$ & $\sim 0$ & {$[6,14]$} \\
\hline & 285 & 0 & $\mathrm{n} / \mathrm{a}$ & 0 & [21] \\
\hline & 276.9 & 0 & $\mathrm{n} / \mathrm{a}$ & 0 & {$[18]$} \\
\hline & 276.8 & $\sim 0$ & $\sim 100$ & $\sim 0$ & This study \\
\hline
\end{tabular}

study ${ }^{[9]}$ as 700 and $890{ }^{\circ} \mathrm{C}$, respectively, and were discarded by Smith and Lee ${ }^{[7]}$ for temperatures closer to the currently accepted values for pure La. The decision is partly supported by a later review by Savitskii ${ }^{[13]}$ that places the temperature of the peritectic $(\mathrm{L}+\mathrm{V} \leftrightarrow \gamma \mathrm{La})$ reaction at $925^{\circ} \mathrm{C}$ and leaving the peritectoid reaction in place. In the calculated diagram by Smith and Lee, ${ }^{[7]}$ the peritectoid reaction is presented as a eutectoid reaction $(\gamma \mathrm{La} \leftrightarrow$ $\mathrm{V}+\beta \mathrm{La})$ instead. The monotectic invariant $\left(\mathrm{L}_{1} \leftrightarrow \mathrm{L}_{2}+\mathrm{V}\right)$ is given as $1680{ }^{\circ} \mathrm{C}$ in all diagrams preceding Smith and Lee ${ }^{[7]}$ and is discarded based on the reasoning that a "large melting point depression $\left(>200^{\circ}\right)$ of $\mathrm{V}$ by the dissolution of $<2$ at.\% La seems unrealistic in view of the constraints of the van's Hoff equation." $[7]$ The invariant temperatures and compositions used by Smith and Lee ${ }^{[7]}$ are supported by an earlier study by Smith et al. ${ }^{[14]}$ that refined the interaction parameters generated using the Miedama approximation. ${ }^{[15,16]}$ The interaction parameters are comparable due to the "smooth systematic trends" that characterize "the physical and chemical behavior of the rare earths." ${ }^{[14]}$

\subsection{V-Y System}

The terminal phases of the V-Y system are V, $\alpha \mathrm{Y}$ (hcp), and $\beta Y$ (bcc) above room temperature. Like the preceding systems, Smith and Lee ${ }^{[7]}$ (see Fig. 1c) highlighted the results of several earlier studies. Aside from the study by Lundin and Klodt ${ }^{[17]}$ and the review by Gschneidner, ${ }^{[8]}$ other studies were viewed skeptically and given no weight. Nonetheless, Lundin et al. ${ }^{[17]}$ provided some experimental data particularly on the eutectic $(\mathrm{L} \leftrightarrow \alpha \mathrm{Y}+\mathrm{V})$ reaction on the Y-rich end. The eutectic temperature is given as $1455^{\circ} \mathrm{C}$ and the composition of the liquid as 88.4 at.\% Y. According to Lundin et al. ${ }^{[17]}$ the solubility of $\mathrm{V}$ in $(\mathrm{Y})$ is $0.3 \pm 0.17$ at. $\% \mathrm{~V}$ and the solubility of $\mathrm{Y}$ in $(\mathrm{V})$ is negligible at the eutectic equilibria. As for the allotropic transition $(\beta Y \leftrightarrow \alpha \mathrm{Y})$, Lundin et al. proposed a depression in the transition temperature based on the speculation "that the solubility of $\mathrm{V}$ in bcc (Y) would be greater than in $\mathrm{cph}$ (Y). ${ }^{\left[{ }^{[7]}\right.}$ Smith and Lee, ${ }^{[7]}$ however, obtained the opposite in their calculated diagram which led to an elevation in the allotropic transition temperature. There is no convincing experimental support for either Lundin-Klodt's catatectic $(\beta \mathrm{Y} \leftrightarrow \alpha \mathrm{Y}+\mathrm{L})$ reaction or Smith-Lee's peritectic ( $\mathrm{L}+$ $\beta Y \leftrightarrow \alpha Y$ ) reaction. However, the present modeling is based on Smith-Lee's assessment. ${ }^{[7]}$

\section{Thermodynamic Models}

The Gibbs energy for each element is defined with respect to its stable state at $298.15 \mathrm{~K}$ and $1 \mathrm{~atm}$. In the CALPHAD method, the Gibbs energy of pure elements is represented as a power series in terms of temperature in the form:

$G=a+b T+c T \ln (T)+\sum_{n} d_{n} T^{n}$

where $a, b, c$, and $d_{n}$ are coefficients and $n$ represents a set of integers typically of the values of 2,3 , and -1 . The thermodynamic data for pure elements are taken from SGTE-PURE- $v 4^{[18]}$ for database compatibility purposes. The Gibbs energy of individual substitutional solution phases (e.g., liquid, bcc, fcc, hcp, and dhcp) was modeled using the substitutional solution model:

$$
\begin{aligned}
& G^{\Phi}=x_{\mathrm{V}}{ }^{\circ} G_{\mathrm{V}}^{\Phi}+x_{\mathrm{RE}}{ }^{\circ} G_{\mathrm{RE}}^{\Phi}+G^{\mathrm{id}}+G_{\mathrm{m}}^{\mathrm{ex}}+G_{\mathrm{m}}^{\mathrm{mag}} \\
& G^{\mathrm{id}}=R T \cdot\left[x_{\mathrm{V}} \ln \left(x_{\mathrm{V}}\right)+x_{\mathrm{RE}} \ln \left(x_{\mathrm{RE}}\right)\right] \\
& G_{\mathrm{m}}^{\mathrm{ex}}=x_{\mathrm{V}} x_{\mathrm{RE}} \cdot \sum_{v=0}^{n}{ }^{v} L_{\mathrm{V}, \mathrm{RE}}\left(x_{\mathrm{RE}}-x_{\mathrm{V}}\right)^{v}
\end{aligned}
$$$$
(\mathrm{Eq} 4 \mathrm{a}, \mathrm{RE}=\mathrm{Ce}, \mathrm{La})
$$$$
G_{\mathrm{m}}^{\mathrm{ex}}=x_{\mathrm{V}} x_{\mathrm{RE}} \cdot \sum_{v=0}^{n}{ }^{v} L_{\mathrm{V}, \mathrm{RE}}\left(x_{\mathrm{V}}-x_{\mathrm{RE}}\right)^{v}
$$$$
(\mathrm{Eq} 4 \mathrm{~b}, \mathrm{RE}=\mathrm{Y})
$$

${ }^{v} L_{\mathrm{V}, \mathrm{RE}}=a_{v}+b_{v} T+c_{v} T \ln (T)$

where RE stands for elements $\mathrm{Ce}$, La or $\mathrm{Y}$; ${ }^{\circ} G_{\mathrm{V}}^{\Phi}$ and ${ }^{\circ} G_{\mathrm{RE}}^{\Phi}$ are the Gibbs energy of pure $\mathrm{V}$ and rare earth elements in the solution phase $\Phi ; G^{\text {id }}$ is the ideal mixing energy; $G_{\mathrm{m}}^{\text {ex }}$ is the excess energy of the phase using the Redlich-Kister polynomial form ${ }^{[19]} ; x_{\mathrm{V}}$ and $x_{\mathrm{RE}}$ are the mole fractions of the constituents; ${ }^{v} L_{\mathrm{V}, \mathrm{RE}}$ is the binary interaction parameter of $\mathrm{V}$ and RE of an order $v, R$ is the gas constant and $T$ is the absolute temperature (K). $G_{\mathrm{m}}^{\mathrm{mag}}$ is the Gibbs energy due to magnetic ordering, but it is set to zero in this study.

\section{Thermodynamic Assessment and Discussion}

The V-Ce, V-La, and V-Y binaries were optimized and the binary interaction parameters are listed in Table 1. To start 
the optimization procedure, a positive temperature-independent interaction parameter was chosen to reproduce the miscibility gap in the liquid phase. A positive temperature-independent interaction parameter is also applied to the solid phases since $\mathrm{V}$ and the rare earths are negligibly soluble in one another. Higher-order temperature-independent interaction parameters are added to adjust the symmetry, invariant temperature and composition and solubility. Emphasis was placed on ensuring the invariant temperatures were within reasonable range of the accepted phase diagram temperatures $\left(10^{\circ} \mathrm{C}\right.$ for monotectic and $5{ }^{\circ} \mathrm{C}$ for the other invariant equilibria unless specified by the diagram). Temperature-dependent interaction parameters (namely $b_{v}$ in Eq. 5) were introduced when using the temperature-independent parameters alone (namely $a_{v}$ in Eq. 5) proved unsatisfactory in reproducing the phase diagrams. All three calculated phase diagrams were based on the currently accepted phase diagrams. ${ }^{[7]}$

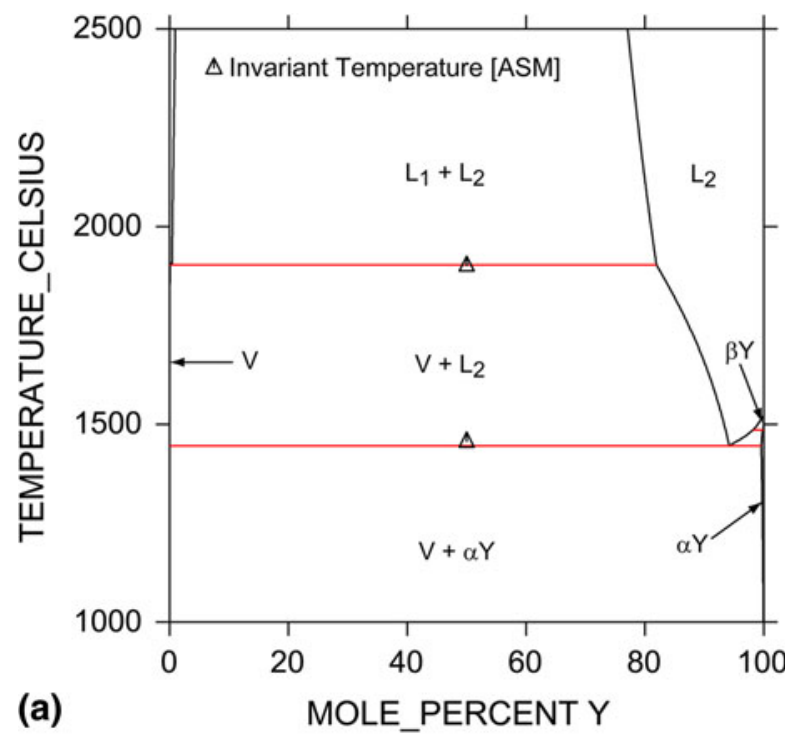

The calculated V-Ce phase diagram as shown in Fig. 2(a)-(c) is an accurate rendering of the currently accepted phase diagram. ${ }^{[7]}$ As seen in Table 2, the composition and temperature for the invariant reactions show reasonable agreement with the currently accepted phase diagram. While attempts were made to fit the experimental data for the peritectic and eutectoid reactions, the shifts in the allotropic transition were incompatible with the limited solubility of $\mathrm{V}$ in (Ce) as shown in Fig. 2(b). The authors noticed that the updated SGTE-Pure v4 database ${ }^{[18]}$ treats the polymorphic transformation temperature of $\gamma \mathrm{Ce} \leftrightarrow \beta \mathrm{Ce}$ at $10{ }^{\circ} \mathrm{C}$, which is based on a 20 -year experimental study by Gschneidner and Pecharsky ${ }^{[20]}$ who discovered that $\gamma \mathrm{Ce}$ is the true standard state of elemental Ce.

The calculated V-La phase diagram as shown in Fig. 3(a)-(c) is in reasonable agreement with the currently accepted phase diagram. ${ }^{[7]}$ As explained earlier, much of the

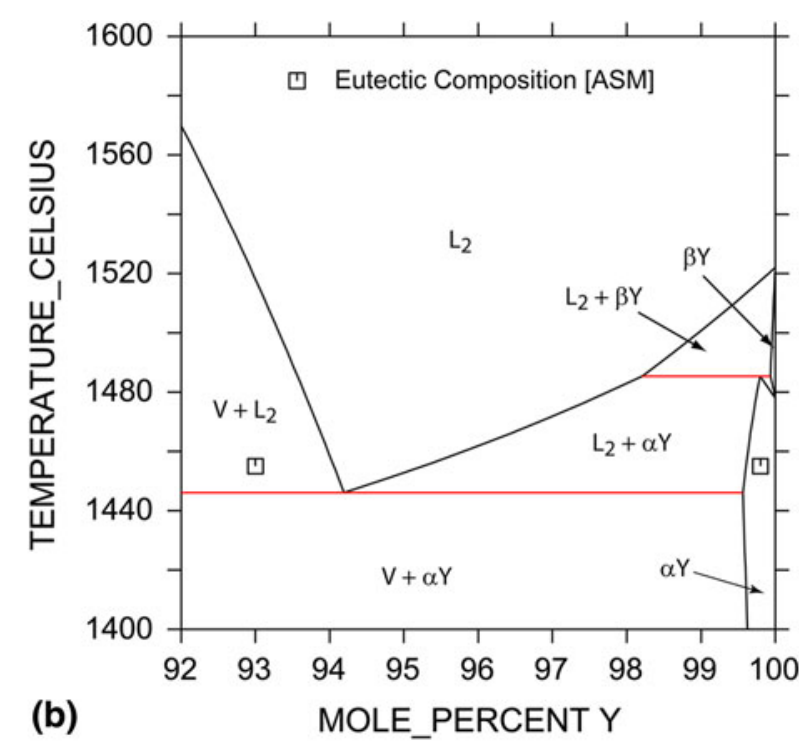

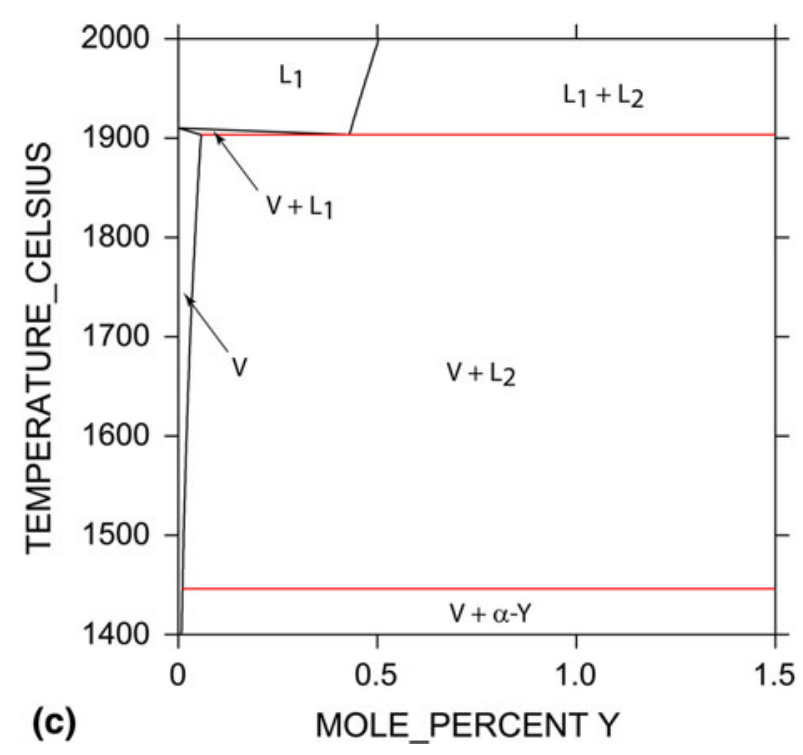

Fig. 4 (a) Calculated phase diagram of the V-Y system compared with the handbook. ${ }^{[6]}$ (b) Enlarged Y-rich side of the V-Y phase diagram. (c) Enlarged V-rich side of the V-Y phase diagram 
experimental data were excluded due to the large shifts in the invariant reactions that were incompatible with the negligible solubility of $\mathrm{La}$ and $\mathrm{V}$. The composition and temperature for the invariant reactions are given in Table 3 for comparison and supports an agreement with the currently accepted phase diagram. ${ }^{[7]}$ As with the currently accepted phase diagram, the allotropic transition $(\gamma \mathrm{La} \leftrightarrow$ $\beta \mathrm{La})$ is represented as a eutectoid $(\gamma \mathrm{La} \leftrightarrow \mathrm{V}+\beta \mathrm{La})$ reaction in the binary La-V system.

The calculated V-Y phase diagram as shown in Fig. 4(a)-(c) is in reasonable agreement with the currently accepted phase diagram. ${ }^{[7]}$ An exception, however, is that the composition of the V-rich liquid of the monotectic reaction $\left(\mathrm{L}_{1} \leftrightarrow\right.$ $\mathrm{V}+\mathrm{L}_{2}$ ) has higher $\mathrm{Y}$ solubility in both $\mathrm{V}$ and liquid than Smith and Lee's calculation. ${ }^{[7]}$ To test the effect on the phase diagram from the solubility at the monotectic reaction, the authors compared various V-Y phase diagrams with a wide range of combination of solubility. The results (not shown) demonstrated that the extremely low solubility even in the liquid phase $(\sim 0.001 \% \mathrm{Y})^{[7]}$ was deemed unreasonable as it tremendously increases the critical point of the liquid miscibility gap. In fact, according to ASM handbook, ${ }^{[6]}$ the liquid at the monotectic point of some analogous binaries such as $\mathrm{Nb}-\mathrm{Y}$ and $\mathrm{Ta}-\mathrm{Y}$ systems has finite $\mathrm{Y}$ solubility (it is $\sim 0.5$ at. $\% \mathrm{Y}$ in $\mathrm{Nb}-\mathrm{Y}$ and $\sim 2$ at. $\% \mathrm{Y}$ in Ta-Y). The composition and temperature for the invariant reactions are given in Table 4 for comparison. The invariant reaction for the allotropic $(\beta Y \leftrightarrow \alpha Y)$ transition is in agreement with Smith-Lee's peritectic $(\mathrm{L}+\beta \mathrm{Y} \leftrightarrow \alpha \mathrm{Y})$ prediction. ${ }^{[14]}$ The eutectic point obtained in the present study is shifted toward Y-rich side by $\sim 6.2$ at.\% compared to the data from Lundin and Klodt. ${ }^{[17]}$ It was not possible to obtain exact fitting to their data ${ }^{[17]}$ without significantly altering the eutectic temperature and the monotectic invariant reaction.

Based on the existing literature, the V-Ce, V-La and V-Y binaries were thermodynamically assessed using the CALPHAD method and the calculated phase diagrams are in reasonable agreement with the currently accepted phase diagrams in the ASM Handbook. ${ }^{[6]}$ However, additional work is necessary to improve the thermodynamic descriptions. For the V-Ce system, it is necessary to collect more accurate data concerning the temperature and composition of invariant reactions. For the V-La system, differential thermal analysis (DTA) could provide additional phase

Table 4 Invariant Reactions in the V-Y System compared with the literature ${ }^{[6,14,17]}$

\begin{tabular}{|c|c|c|c|c|c|}
\hline \multirow{2}{*}{$\begin{array}{l}\text { Invariant reactions } \\
\mathrm{L}_{1} \leftrightarrow \mathrm{L}_{2}+\mathrm{V}\end{array}$} & \multirow{2}{*}{$\frac{\boldsymbol{T},{ }^{\circ} \mathrm{C}}{1900}$} & \multicolumn{3}{|c|}{ Y concentration (at. $\%$ ) } & \multirow{2}{*}{$\frac{\text { Reference }}{[17]}$} \\
\hline & & 0.06 & 85.2 & $<0.06$ & \\
\hline & 1908 & $10^{-3}$ & 82 & $10^{-4}$ & {$[6,14]$} \\
\hline & 1903 & 0.43 & 81.94 & 0.06 & This study \\
\hline \multirow[t]{3}{*}{$\mathrm{L}+\beta \mathrm{Y} \leftrightarrow \alpha \mathrm{Y}$} & 1490 & $\mathrm{n} / \mathrm{a}$ & $\mathrm{n} / \mathrm{a}$ & $\mathrm{n} / \mathrm{a}$ & {$[17]$} \\
\hline & 1485 & 99.94 & 98.3 & 99.7 & {$[6,14]$} \\
\hline & 1485 & 99.94 & 98.21 & 99.8 & This study \\
\hline \multirow[t]{3}{*}{$\mathrm{L} \leftrightarrow \mathrm{V}+\alpha \mathrm{Y}$} & 1455 & 88.39 & $\sim 0$ & 99.65 & {$[17]$} \\
\hline & 1450 & 93 & $\sim 0$ & 99.9 & {$[6,14]$} \\
\hline & 1450 & 94.19 & $\sim 0$ & 99.56 & This study \\
\hline
\end{tabular}

equilibria information such as composition and temperature of invariant reactions and liquidus boundaries. For the V-Y system, the thermodynamic description could be enhanced by experimentally determining (1) the compositions at the monotectic reaction and (2) whether the allotropic transition reaction is peritectic or catatectic in the Y-rich side and the corresponding compositions and temperature.

\section{Summary}

The experimental phase equilibria data and thermodynamics of V-Ce, V-La, and V-Y binary systems are reviewed. Based on limited available experimental data and ASM handbook, a self-consistent thermodynamic description of these systems is obtained by thermodynamic modeling of the Gibbs energy of individual phases in these systems via the CALPHAD approach.

\section{Acknowledgments}

This research was performed in support of the Advance Research Program of the NETL's Strategic Center for Coal. This research was supported in part by an appointment (W.C.) to the US Department of Energy (DOE) Postgraduate Research Program at NETL administrated by the Oak Ridge Institute for Science and Education. MCG thanks Vijay Jain for helpful comments on the manuscript.

\section{References}

1. D.L. Smith, H.M. Chung, B.A. Loomis, H. Matsui, S. Votinov, and W. Van Witzenburg, Development of Vanadium-Base Alloys for Fusion First Wall/Blanket Applications, International Symposium on Fusion Nuclear Technology, 1994

2. C.Y. Seo, J.H. Kim, P.S. Lee, and J.Y. Lee, Hydrogen Storage Properties of Vanadium-Based B.C.C. Solid Solution Metal Hydrides, J. Alloys Compd., 2003, 348, p 252-257

3. G. Bauer, V. Güther, H. Hess, A. Otto, O. Roidl, H. Roller, and S. Sattelberger, Vanadium and Vanadium Compounds, WileyVCH Verlag GmbH, Weinheim, Germany, 2002

4. M. Fujiwara, K. Natesan, M. Satou, A. Hasegawa, and K. Abe, Effects of Doping Elements on Oxidation Properties of V-CrTi Type Alloys in Several Environments, J. Nuclear Mater., 2002, 307, p 601-604

5. H. Kurishita, T. Kuwabara, and A. Hasegawa, Development of Fine-Grained V-28Cr-2.3Y and V-52Cr-1.8Y Alloys with Superior Mechanical Properties, Mater. Sci. Eng. A, 2006, 433, p 32-38

6. T.B. Massalski, P.R. Subramanian, H. Okamoto, and L. Kacprzak, Binary Alloy Phase Diagrams, Vol 1-3, 2nd ed., ASM International, Materials Park, OH, 1990

7. J.F. Smith and K.J. Lee, Phase Diagrams of Binary Vanadium Alloys, ASM International, Materials Park, OH, 1989

8. K.A. Gschneidner, Jr., Binary Alloy Systems, Rare Earth Alloys, Nostrand Company, Princeton, NJ, 1961

9. Y.V. Efimov, Limited Miscibility in the Liquid State in Binary Alloys of Vanadium with Copper, Lanthanum and Cerium, Russ. Metall. (Translation), 1967, 6, p 86-89 
10. E.M. Savitskii, V.V. Baron, and Y.V. Efimov, Equilibrium Diagram of the Cerium-Vanadium System, Russ. J. Inorg. Chem., 1962, 7, p 359-360

11. E.M. Savitski, Y.V. Efimov, N.D. Kozlova, and O.I. Zvolinsk, Influence of Rare-Earth Metals on Superconductivity of Vanadium Niobium, and Tantalum, Dokl. Akad. Nauk SSSR, 1973, 213, p 826-829

12. E.M. Savitskii, V.V. Baron, and Y.V. Efimov, Trudy Inst. Met. in A. A. Baikova Akad. Nauk SSSR, 1960, 5, p 166-173

13. E.M. Savitskii, Redkozemel'nye Metally, Splavy I Soedineniya, Izdatel'stvo Nauka, Moscow, 1973, p 310-316

14. J.F. Smith, K.J. Lee, and D.M. Martin, Binary Rare EarthVanadium Systems, CALPHAD, 1988, 12, p 89-96

15. A.R. Miedema, Heat of Formation of Alloys, Philips Tech. Rev., 1976, 36, p 217-231
16. A.R. Miedema and A.K. Niessen, The Enthalpy of Solution for Solid Binary-Alloys of 2 4d-Transition Metals, CALPHAD, 1983, 7, p 27-36

17. C.E. Lundin and D.T. Klodt, Alloy Systems of Group VA Metals With Yttrium, J. Inst. Met., 1962, 90, p 341-347

18. A. Dinsdale, SGTE Data for Pure Elements, CALPHAD, 1991, 15, p 317-425

19. O. Redlich and A.T. Kister, Algebraic Representation of Thermodynamic Properties and the Classification of Solutions, Ind. Eng. Chem., 1948, 40, p 345-348

20. K.A. Gschneidner, Jr. and V.K. Pecharsky, The Standard State of Cerium, J. Phase Equil., 1999, 20, p 612-614

21. K.A. Gschneidner, Jr. and F.W. Calderwood, Hankbook on the Physics and Chemistry of Rare Earths, North-Holland Publishing Co., Amsterdam, 1986 